\title{
Model Study on a Swirl Motion of a Bubbling Jet Generated in a Wastewater Bath Covered with Top Oil Layer
}

\author{
Taku TAMAMORI, Manabu IGUCHI ${ }^{1)}$ and Moriyoshi SHITARA ${ }^{2)}$ \\ Huens Co., Ltd., South 17, East 15, Obihiro, Hokkaido 080-0802 Japan. \\ 1) Division of Materials Science and Engineering, Graduate School of Engineering, Hokkaido University, North 13, West 8 , \\ Kita-ku, Sapporo 060-8628 Japan. $\quad$ 2) Formerly at Huens Co., Ltd., now at Graduate Student, Graduate School of \\ Engineering, Hokkaido University, North 13, West 8, Kita-ku, Sapporo, Hokkaido 060-8628 Japan.
}

(Received on February 8, 2005; accepted on May 25, 2005)

\begin{abstract}
Experimental investigation was carried out on a swirl motion of a bottom blown bubbling jet in the presence of a top oil layer. Water was used as the lower liquid and silicone oil was used as the top oil. The kinematic viscosity of the silicone oil was changed over a wide range. The occurrence region of the swirl motion became narrow as the kinematic viscosity of the silicone oil, $v_{0}$, increased. Silicone oil did not affect the period of swirl motion, $T_{s}$. As $v_{0}$ increased, the starting time of the swirl motion, $T_{s, s^{\prime}}$ increased, whereas the amplitude, $A$, and the damping time of the swirl motion, $T_{s, d}$ decreased. An apparent kinematic viscosity, $v_{\mathrm{app}}$, was introduced for correlating $A, T_{\mathrm{s}, \mathrm{s}}$ and $T_{\mathrm{s}, \mathrm{d}}$. Empirical equations were proposed for these quantities as functions of $v_{\text {app }}$
\end{abstract}

KEY WORDS: wastewater treatment; gas injection; swirl motion; bubbling jet; top oil.

\section{Introduction}

A swirl motion of a bottom blown bubbling jet finds its wide applications in parlor wastewater and sludge treatment. ${ }^{1,2)}$ A mixture of ozone and air was used as the injection gas. The $\mathrm{BOD}_{5}$ and $\mathrm{COD}_{\mathrm{Mn}}$ initially contained in wastewater and suspended solid particles in sludge were significantly decreased in the presence of the swirl motion. Dioxins also were satisfactorily decomposed. ${ }^{3)}$

Detailed information on the swirl motion is required for further enhancement of the treatment efficiency of these processes. Previous researchers ${ }^{4-11)}$ focused on the occurrence condition of the swirl motion of a bubbling jet generated with a centered bottom nozzle and investigated some basic characteristics such as the period, amplitude, starting time and damping time of the swirl motion. In these experiments water and air were mainly used as the working fluids. In practical applications, an oil layer sometimes covers the surface of a wastewater bath. The effect of the top oil layer on the swirl motion however is not understood yet. In this model study water, air, and some kinds of silicone oils of different kinematic viscosities were used as the working fluids to investigate the basic characteristics of the swirl motion in the presence of the top oil layer.

\section{Experimental Apparatus and Procedure}

Figure 1 shows a schematic diagram of the experimental apparatus. The test vessel was made of transparent acrylic resin. Three vessels of different diameters were used; $D=130 \mathrm{~mm}, 200 \mathrm{~mm}$, and $309 \mathrm{~mm}$. Air was injected into the bath through a single-hole nozzle settled on the center of the bottom wall. A swirl motion of the deep-water wave type was mentioned in this study. According to the previous study, ${ }^{8)}$ this swirl motion preferably occurs for an aspect ratio, $H_{\mathrm{L}} / D$, between approximately 0.3 and unity, where $H_{\mathrm{L}}$ $\left(=H_{\mathrm{L} 1}+H_{\mathrm{L} 2}\right)$ is the total bath depth, $H_{\mathrm{L} 1}$ is the thickness of the upper oil layer, and $H_{\mathrm{L} 2}$ is the lower water layer. The inner diameter of the nozzle does not affect the swirl motion of a bubbling jet in the absence of the top oil layer. The reason is that the bath is agitated mainly through an effect of the buoyancy force acting on bubbles. The same situation is realized even if a top oil layer exists. The inner di-

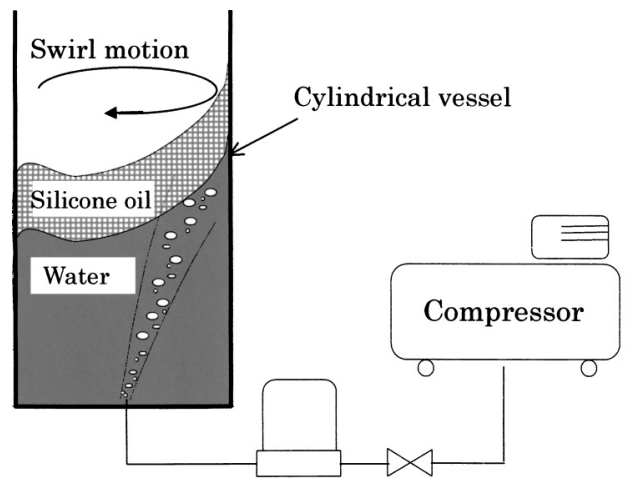

Mass flow controller Regulator

\begin{tabular}{|l|}
\hline $\begin{array}{c}\text { Inner diameter of cylindrical vessel } \\
D: 130 \mathrm{~mm}, 200 \mathrm{~mm}, 309 \mathrm{~mm}\end{array}$ \\
\hline Inner diameter of nozzle $d_{\mathrm{ni}}: 2 \mathrm{~mm}$ \\
\hline Air flow rate $Q_{\mathrm{g}}: 0<Q_{\mathrm{g}} \leqq 720 \mathrm{~cm}^{3} / \mathrm{s}$ \\
\hline
\end{tabular}

Fig. 1. Experimental apparatus. 
Table 1. Physical properties of fluids at $298 \mathrm{~K}$.

\begin{tabular}{|c|c|c|c|}
\hline & Density & $\begin{array}{c}\text { Kinematic } \\
\text { viscosity } \\
\nu\left(\mathrm{kg} / \mathrm{m}^{3}\right)\end{array}$ & $\begin{array}{c}\text { Surface } \\
\text { tension } \\
\sigma(\mathrm{mm} / \mathrm{s})\end{array}$ \\
\hline Air & 1.18 & 15.6 & \\
\hline Water & 997 & 0.891 & 72.7 \\
\hline $\begin{array}{c}\text { Silicone oil } \\
10 \mathrm{~mm}^{2} / \mathrm{s}\end{array}$ & 935 & 10 & 20.1 \\
\hline $\begin{array}{c}\text { Silicone oil } \\
50 \mathrm{~mm}^{2} / \mathrm{s}\end{array}$ & 960 & 50 & 20.8 \\
\hline $\begin{array}{l}\text { Silicone oil } \\
100 \mathrm{~mm}^{2} / \mathrm{s}\end{array}$ & 965 & 100 & 20.9 \\
\hline
\end{tabular}

ameter of the nozzle, $d_{\mathrm{ni}}$, therefore was kept at $2.0 \mathrm{~mm}$. The airflow rate, $Q_{\mathrm{g}}$, was adjusted with a mass flow controller. The physical properties of the working fluids at $298 \mathrm{~K}$ are listed in Table 1. The kinematic viscosity of silicone oil, $v_{\mathrm{o}}$, was changed from 10 to $100 \mathrm{~mm}^{2} / \mathrm{s}$.

The amplitude of the swirl motion was evaluated on the side wall of the vessel. ${ }^{9}$ ) A half of the difference between the highest and lowest levels of the bath surface was defined as the amplitude, $A$. The starting time, $T_{\mathrm{s}, \mathrm{s}}$, was defined as the period from the start of gas injection to the moment at which the swirl motion attained a steady state. The damping time of the swirl motion was defined as the period from the stoppage of gas injection to the moment at which the amplitude of the swirl motion on the sidewall of the vessel became less than $0.5 \mathrm{~mm}$.

\section{Experimental Results and Discussion}

\subsection{Occurrence Condition of Swirl Motion}

The aspect ratio of the water bath, $H_{\mathrm{L} 2} / D$, was kept at 0.5 . This is because a swirl motion is the most likely to occur around this aspect ratio and beneficial for practical applications. Figures 2 though $\mathbf{4}$ show the boundaries of the occurrence regions of swirl motion for three different vessel diameters. At first, an explanation will be given on the results shown in Fig. 2. Solid circular symbols denote the boundary of the occurrence region for a water bath. A swirl motion of a bubbling jet generated in the water bath occurred in the region enclosed with these symbols. In this study the aspect ratio of the water bath was kept at 0.5 . A top oil layer of a prescribed aspect ratio, $H_{\mathrm{L} 1} / D$, was placed on the water bath. A critical gas flow rate for the occurrence of the swirl motion was determined for that aspect ratio. Subsequently, the aspect ratio was gradually increased until the swirl motion never occurs under the present gas flow rate regime. The critical gas flow rate thus determined was represented by open symbols for the three kinematic viscosities. Accordingly, the swirl motion occurred in the region enclosed with the solid line $\left(H_{\mathrm{L} 2} / D=0.5\right)$ and the open symbols, as indicated by "Swirl" in Fig. 2. The situation is the same in Figs. 3 and 4. The occurrence region was hardly affected by the kinematic viscosity of silicone oil, $v_{\mathrm{o}}$, for $D=130 \mathrm{~mm}$. The effect of $v_{\mathrm{o}}$ became significant with an increase in the vessel diameter, $D$. The occurrence region became narrow with an increase in $v_{\mathrm{o}}$ because much energy was consumed in the upper silicone oil layer.

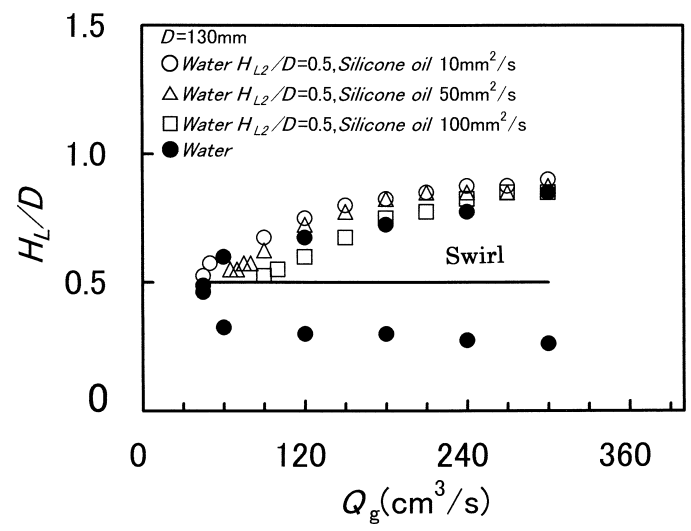

Fig. 2. Occurrence region of swirl motion for $D=130 \mathrm{~mm}$.

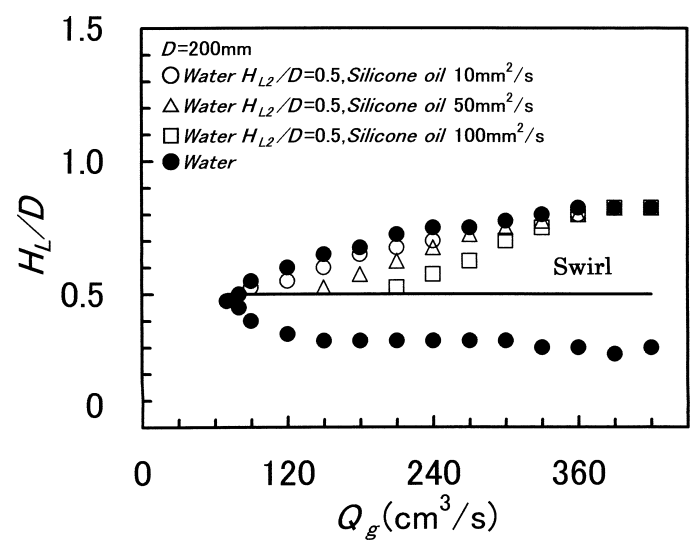

Fig. 3. Occurrence region of swirl motion for $D=200 \mathrm{~mm}$.

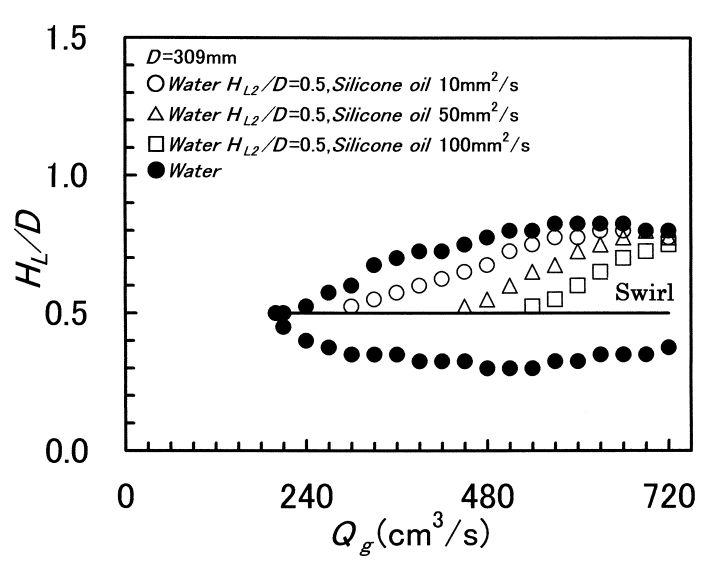

Fig. 4. Occurrence region of swirl motion for $D=309 \mathrm{~mm}$.

When a swirl motion occurred, water and silicone oil were strongly mixed in the bath to result in emulsification of the oil. We therefore used the following apparent kinematic viscosity, $v_{\text {app }}$, for the mixture of silicone oil and water.

$$
\begin{aligned}
& v_{\text {app }}=\mu_{\text {app }} / \rho_{\mathrm{m}} \\
& \mu_{\text {app }}=\left[\mu_{\mathrm{w}} /(1-\phi)\right]\left[1+1.5 \phi \mu_{\mathrm{o}} /\left(\mu_{\mathrm{o}}+\mu_{\mathrm{w}}\right)\right] \text {. } \\
& \rho_{\mathrm{m}}=\phi \rho_{\mathrm{o}}+(1-\phi) \rho_{\mathrm{w}} \\
& \phi=V_{\mathrm{L} 1} / V_{\mathrm{L}} \\
& V_{\mathrm{L}}=V_{\mathrm{L} 1}+V_{\mathrm{L} 2} \\
& V_{\mathrm{L} 1}=\pi D^{2} H_{\mathrm{L} 1} / 4
\end{aligned}
$$




$$
V_{\mathrm{L} 2}=\pi D^{2} H_{\mathrm{L} 2} / 4
$$

where $\mu_{\text {app }}$ is the apparent dynamic viscosity, ${ }^{12,13)} \rho_{\mathrm{m}}$ is the mean density of the silicone oil and water mixture, $\phi$ is the volume fraction of silicone oil, $\rho_{\mathrm{o}}$ is the density of silicone oil, $\rho_{\mathrm{w}}$ is the density of water, $\mu_{\mathrm{w}}$ is the dynamic viscosity of water, and $\mu_{\mathrm{o}}$ is the dynamic viscosity of silicone oil, $V_{\mathrm{L}}$ is the total volume of the bath, and $V_{\mathrm{L} 1}$ and $V_{\mathrm{L} 2}$ are the volumes of the upper and lower layers, respectively. The adequacy of Eq. (1) was confirmed using a propeller type torque meter.

\subsection{Period of Swirl Motion}

According to the previous study, ${ }^{1)}$ the period of a swirl motion of a bubbling jet, $T_{\mathrm{s}}$, in the absence of a top oil layer can be approximated by the theoretical solution for the period of the rotary sloshing caused by an external oscillation of a cylindrical vessel. ${ }^{12,14,15)}$

$$
T_{\mathrm{s}}=2 \pi /\left[\left(2 g \varepsilon_{1} / D\right) \tanh \left(2 \varepsilon_{1} H_{\mathrm{L}} / D\right)\right]^{1 / 2} .
$$

where $g$ is the acceleration due to gravity and $\varepsilon_{1}(=1.841)$ is the first zero of the Bessel function, $J_{1}{ }^{\prime}(\varepsilon)$.

Figures 5 through 7 show the measured values of the period of swirl motion for three different vessels. Equation (8) was indicated by a solid line in every figure. The measured values of the period were slightly overestimated by this equation for every vessel. The deviation was less than $7 \%$. The top oil layer therefore hardly affected the period of swirl motion.

\subsection{Amplitude of Swirl Motion}

The amplitude, $A$, decreased with an increase in the kinematic viscosity of silicone oil, $v_{0}$, and increased with an increase in the gas flow rate, $Q_{\mathrm{g}}$, just as in the case of a highly viscous liquid bath without a top oil layer. ${ }^{11)}$ The apparent kinematic viscosity, $v_{\text {app }}$, introduced in the preceding section will be applied to correlating the measured values of the amplitude of swirl motion.

The following empirical equation was previously introduced for the amplitude of a swirl motion in a bath without a top oil layer. ${ }^{11)}$

$$
\begin{gathered}
A / D=0.224\left[\operatorname{Re}^{1 / 2}\left\{H_{\mathrm{L}} Q_{\mathrm{g}} /\left(D^{7 / 2} g^{1 / 2}\right)\right\}\right]^{0.30} \\
\operatorname{Re}=\left(Q_{\mathrm{g}}^{2} / g\right)^{2 / 5}(g / D)^{1 / 2} / v_{\mathrm{w}} \cdots \cdots \cdots \cdots
\end{gathered}
$$

where Re is the Reynolds number and $v_{\mathrm{w}}$ is the kinematic viscosity of water. The quantity, $H_{\mathrm{L}} Q_{\mathrm{g}} /\left(D^{7 / 2} \mathrm{~g}^{1 / 2}\right)$, is rewritten as $\left(H_{\mathrm{L}} / D\right)\left[\left(Q_{\mathrm{g}} / D^{2}\right) /(g D)^{1 / 2}\right]$, where $H_{\mathrm{L}} / D$ is the aspect ratio and $\left(Q_{\mathrm{g}} / D^{2}\right) /(g D)^{1 / 2}$ is a modified Froude number. Accordingly, the amplitude depends on the Reynolds number, aspect ratio and modified Froude number, as discussed in the previous paper. ${ }^{9)}$ Equation (9) was not adequate for correlating the measured values of the amplitude.

The kinematic viscosity, $v_{\mathrm{w}}$, in Eq. (10) was replaced by the apparent kinematic viscosity, $v_{\text {app}}$, expressed in Eq. (1).

$$
\begin{gathered}
A / D=0.224\left[\operatorname{Re}_{\text {app }}^{1 / 2}\left\{H_{\mathrm{L}} Q_{\mathrm{g}} /\left(D^{7 / 2} g^{1 / 2}\right)\right\}\right]^{0.30} \ldots \\
\operatorname{Re}_{\text {app }}=\left(Q_{\mathrm{g}}^{2} / g\right)^{2 / 5}(g / D)^{1 / 2} / v_{\text {app }} \cdots \cdots \cdots \cdots
\end{gathered}
$$

Equation (11) still overestimated the measured values, and accordingly, the coefficient of Eq. (11) was further

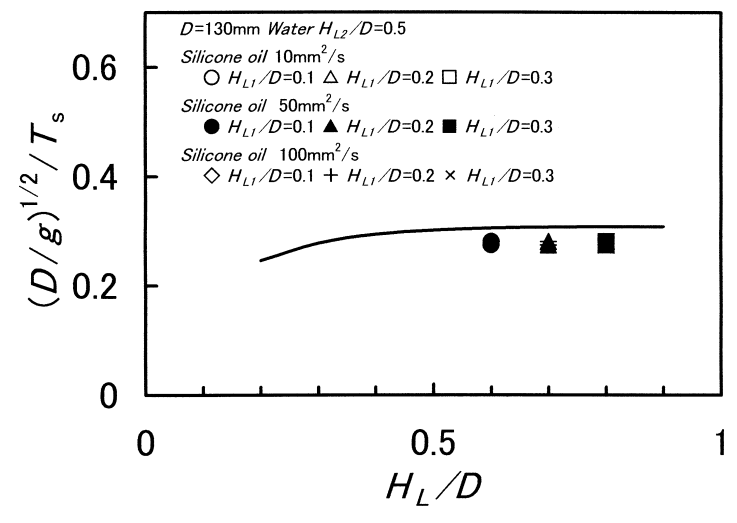

Fig. 5. Period of swirl motion for $D=130 \mathrm{~mm}$.

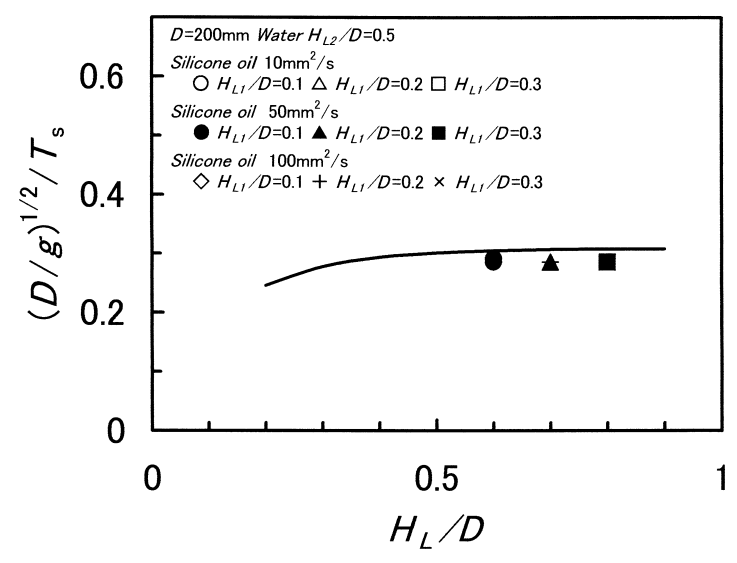

Fig. 6. Period of swirl motion for $D=200 \mathrm{~mm}$.

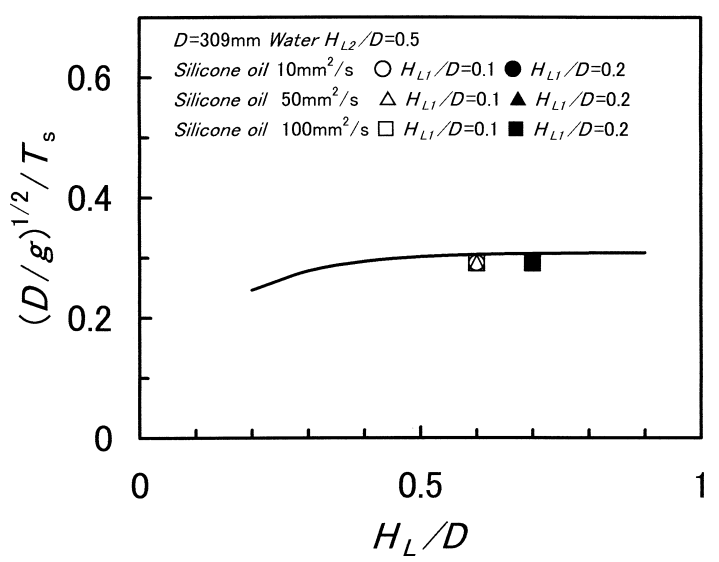

Fig. 7. Period of swirl motion for $D=309 \mathrm{~mm}$.

modified to give:

$$
A / D=0.138\left[\operatorname{Re}_{\text {app }}^{1 / 2}\left\{H_{\mathrm{L}} Q_{\mathrm{g}} /\left(D^{7 / 2} g^{1 / 2}\right)\right\}\right]^{0.30}
$$

Figures 8 through $\mathbf{1 0}$ show the measured values of the amplitude for the three vessels. Figures 9 and 10 demonstrate that the measured values can be satisfactorily approximated by Eq. (13). However, an effect of $v_{\mathrm{o}}$ can still be seen in Fig. 8. Further experiments are required for explaining this effect.

\subsection{Starting Time of Swirl Motion}

The starting time increased as the vessel diameter, $D$, and the kinematic viscosity of silicone oil, $v_{0}$, increased but it decreased with an increase in the gas flow rate, $Q_{\mathrm{g}}$. 


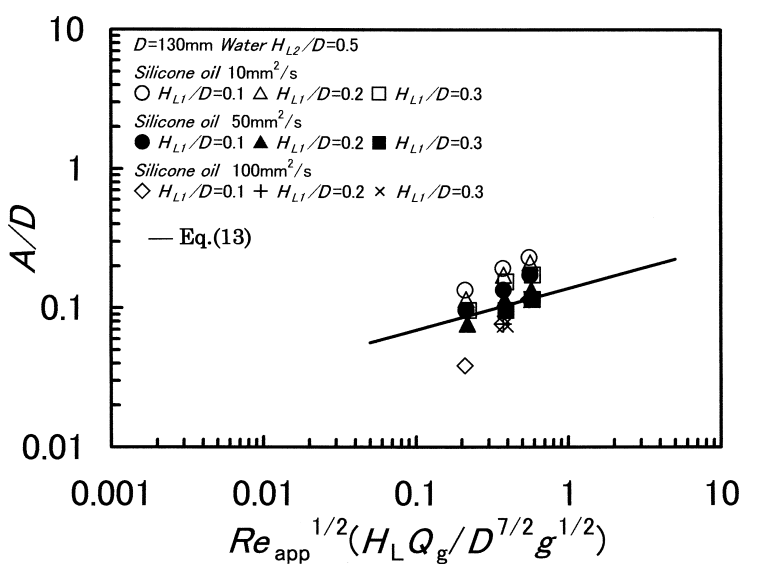

Fig. 8. Amplitude of swirl motion for $D=130 \mathrm{~mm}$.

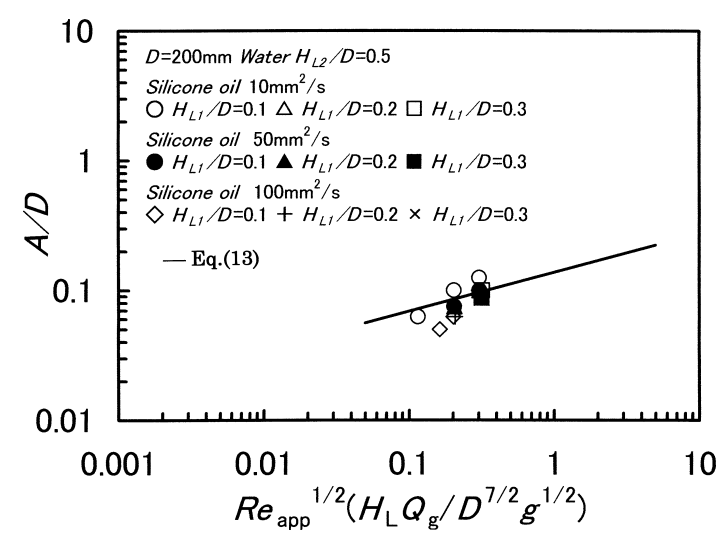

Fig. 9. Amplitude of swirl motion for $D=200 \mathrm{~mm}$.

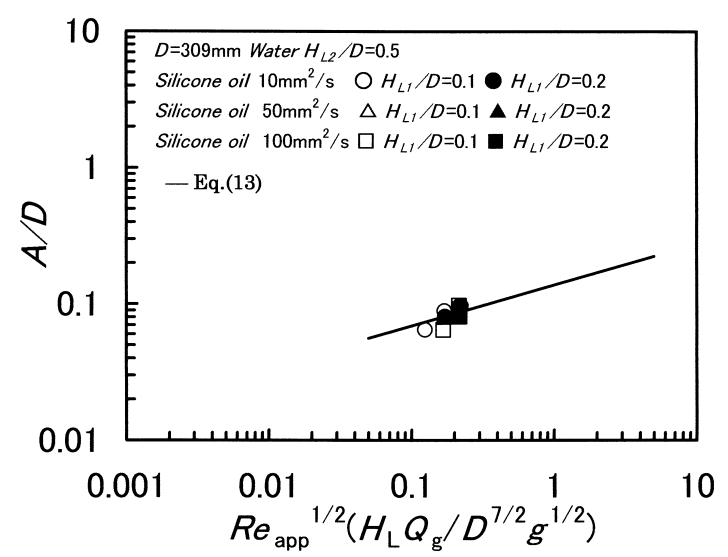

Fig. 10. Amplitude of swirl motion for $D=309 \mathrm{~mm}$.

Concerning a swirl motion in a bath without a top oil layer, the starting time can be predicted by the following empirical equation. ${ }^{11)}$

$$
T_{\mathrm{s}, \mathrm{s}}(g / D)^{1 / 2}=36\left[\operatorname{Re}^{1 / 2}\left\{H_{\mathrm{L}} Q_{\mathrm{g}} /\left(D^{7 / 2} g^{1 / 2}\right)\right\}\right]^{-1 / 2}
$$

By referring to the above-mentioned correlation for the amplitude, Eq. (14) was modified as follows:

$$
T_{\mathrm{s}, \mathrm{s}}(g / D)^{1 / 2}=36\left[\operatorname{Re}_{\text {app }}^{1 / 2}\left\{H_{\mathrm{L}} Q_{\mathrm{g}} /\left(D^{7 / 2} g^{1 / 2}\right)\right\}\right]^{-1 / 2} \ldots
$$

Figures 11 through 13 show the measured values of the starting time of a swirl motion for the three vessels together with Eq. (15). The data in these figures are nearly distributed around Eq. (15) within a scatter inherent in Eq. (15),

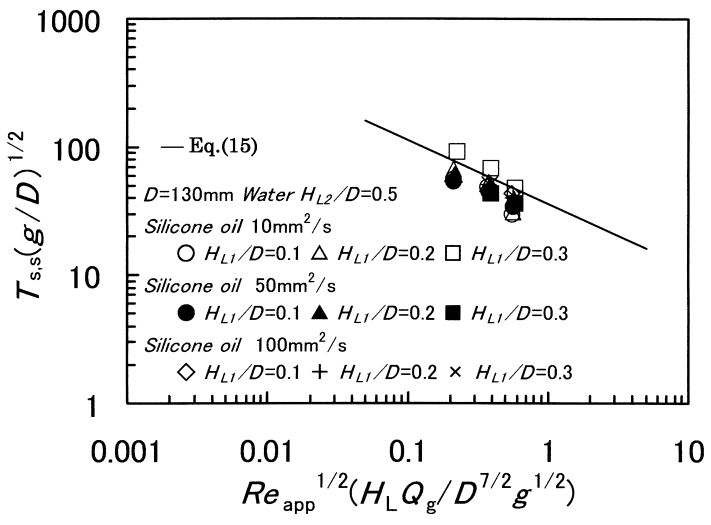

Fig. 11. Starting time of swirl motion for $D=130 \mathrm{~mm}$.

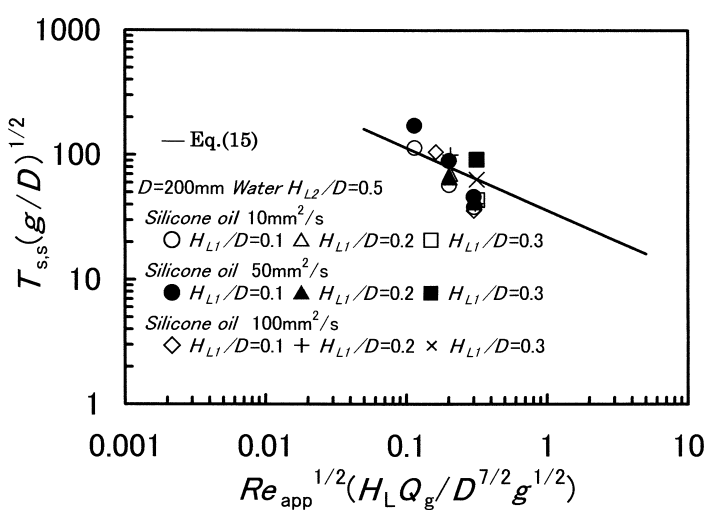

Fig. 12. Starting time of swirl motion for $D=200 \mathrm{~mm}$.

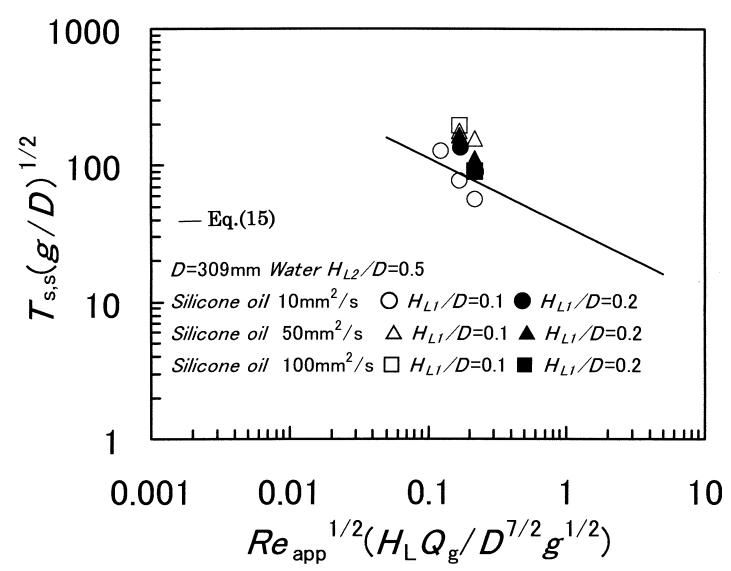

Fig. 13. Starting time of swirl motion for $D=309 \mathrm{~mm}$.

and accordingly, the starting time can be satisfactorily approximated by Eq. (15) under the present experimental conditions.

\subsection{Damping Time of Swirl Motion}

The damping time decreased with an increase in the kinematic viscosity of silicone oil, while increased with an increase in the bath depth. The following empirical equation was proposed for the damping time of a swirl motion in a bath without a top oil layer. ${ }^{11)}$

$$
T_{\mathrm{s}, \mathrm{d}} Q_{\mathrm{g}} / D^{3}=11\left[\operatorname{Re}^{1 / 2}\left\{H_{\mathrm{L}} Q_{\mathrm{g}} /\left(D^{7 / 2} g^{1 / 2}\right)\right\}\right]^{0.91} .
$$

Equation (16) was modified to give

$$
T_{\mathrm{s}, \mathrm{d}} Q_{\mathrm{g}} / D^{3}=11\left[\operatorname{Re}_{\mathrm{app}}^{1 / 2}\left\{H_{\mathrm{L}} Q_{\mathrm{g}} /\left(D^{7 / 2} g^{1 / 2}\right)\right\}\right]^{0.91}
$$




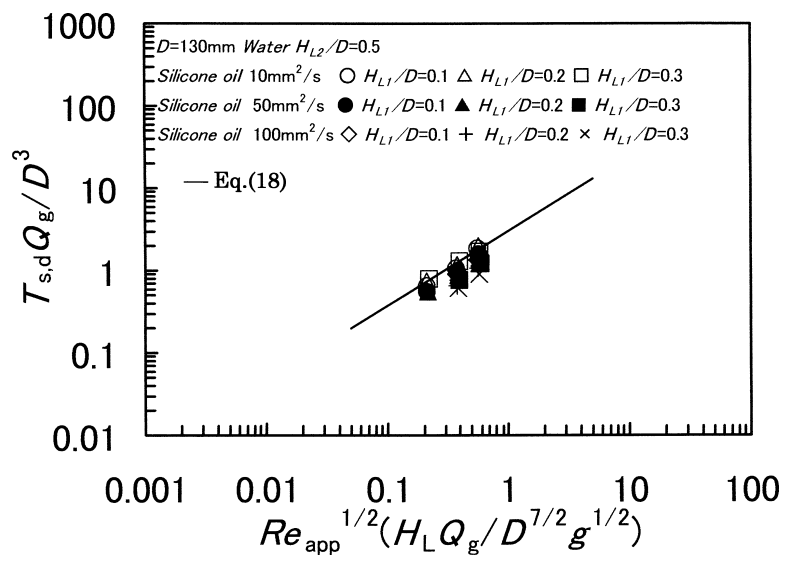

Fig. 14. Damping time of swirl motion for $D=130 \mathrm{~mm}$.

Equation (17) overestimated the measured values of $T_{\mathrm{s}, \mathrm{d}}$. Accordingly, the coefficient of Eq. (17) was modified to fit the presently obtained values.

$$
T_{\mathrm{s}, \mathrm{d}} Q_{\mathrm{g}} / D^{3}=3.0\left[\operatorname{Re}_{\text {app }}^{1 / 2}\left\{H_{\mathrm{L}} Q_{\mathrm{g}} /\left(D^{7 / 2} g^{1 / 2}\right)\right\}\right]^{0.91}
$$

Figures 14-16 show that the measured values of the damping time are satisfactorily approximated by Eq. (18). Many silicone oil droplets rose toward the bath surface after the stoppage of gas injection. This rising motion of silicone oil droplet suppressed the tangential motion of liquid in the bath, and hence, decreased the damping time significantly.

\section{Conclusions}

Water was filled in a cylindrical vessel at an aspect ratio of 0.5. Silicone oil was placed on the water bath. The kinematic viscosity of the silicone oil and the thickness of the silicone oil layer were varied over a wide range. A swirl motion of the deep-water wave type appeared when the bath was agitated by gas injection. Main findings obtained on the basic characteristics of the swirl motion can be summarized as follows:

(1) The occurrence region of the swirl motion became narrow as the kinematic viscosity of silicone oil increased.

(2) The period, $T_{\mathrm{s}}$, amplitude, $A$, starting time, $T_{\mathrm{s}, \mathrm{s}}$, and damping time, $T_{\mathrm{s}, \mathrm{d}}$, of the swirl motion were approximated by the following theoretical and empirical equations.

$$
\begin{gathered}
T_{\mathrm{s}}=2 \pi /\left[\left(2 g \varepsilon_{1} / D\right) \tanh \left(2 \varepsilon_{1} H_{\mathrm{L}} / D\right)\right]^{1 / 2} \ldots \ldots . . \\
A / D=0.138\left[\operatorname{Re}_{\text {app }}^{1 / 2}\left\{H_{\mathrm{L}} Q_{\mathrm{g}} /\left(D^{7 / 2} g^{1 / 2}\right)\right\}\right]^{0.30} \ldots . \\
T_{\mathrm{s}, \mathrm{s}}(g / D)^{1 / 2}=36\left[\operatorname{Re}_{\text {app }}^{1 / 2}\left\{H_{\mathrm{L}} Q_{\mathrm{g}} /\left(D^{7 / 2} g^{1 / 2}\right)\right\}\right]^{-1 / 2} . \\
T_{\mathrm{s}, \mathrm{d}} Q_{\mathrm{g}} / D^{3}=3.0\left[\operatorname{Re}_{\text {app }}^{1 / 2}\left\{H_{\mathrm{L}} Q_{\mathrm{g}} /\left(D^{7 / 2} g^{1 / 2}\right)\right\}\right]^{0.91} \ldots .
\end{gathered}
$$

\section{Nomenclature}

$A$ : Amplitude of swirl motion

$D$ : Vessel diameter

$d_{\text {ni }}$ : Inner diameter of nozzle

$H$ : Vessel height

$H_{\mathrm{L}}: \quad$ Bath depth $\left(=H_{\mathrm{L} 1}+H_{\mathrm{L} 2}\right)$

$H_{\mathrm{L} 1}$ : Thickness of silicone oil layer

$H_{\mathrm{L} 2}$ : Thickness of water layer

$Q_{\mathrm{g}}$ : Gas flow rate

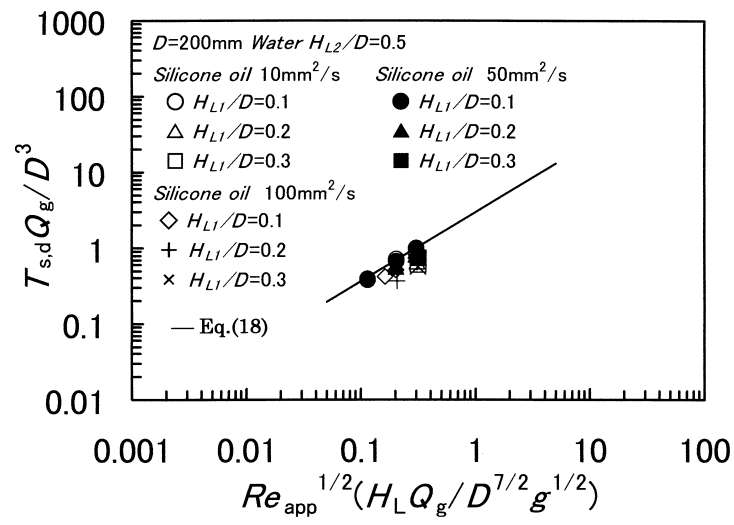

Fig. 15. Damping time of swirl motion for $D=200 \mathrm{~mm}$.

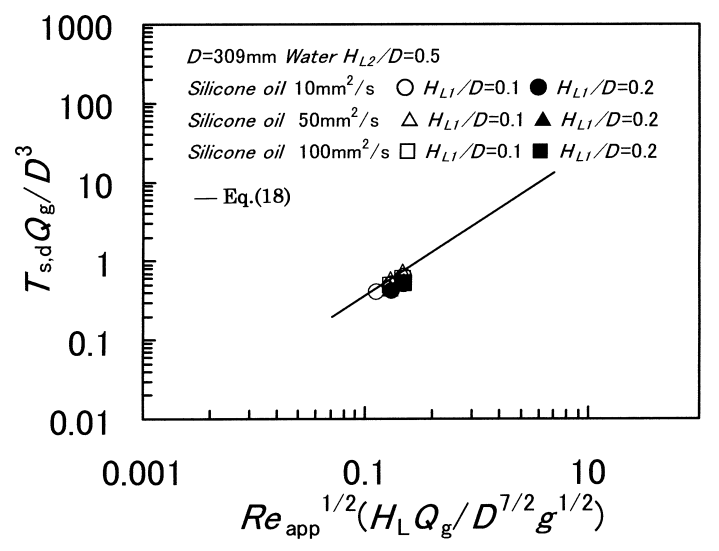

Fig. 16. Damping time of swirl motion for $D=309 \mathrm{~mm}$.

$T_{\mathrm{s}}:$ Period of swirl motion

$T_{\mathrm{s}, \mathrm{d}}$ : Damping time of swirl motion

$T_{\mathrm{s}, \mathrm{s}}:$ Starting time of swirl motion

$V_{\mathrm{L}}:$ Volume of bath $\left(=V_{\mathrm{L} 1}+V_{\mathrm{L} 2}\right)$

$V_{\mathrm{L} 1}$ : Volume of silicone oil

$V_{\mathrm{L} 2}$ : Volume of water

$\phi$ : Volume fraction of silicone oil $\left(=V_{\mathrm{L} 1} / V_{\mathrm{L}}\right)$

$v_{\text {app }}:$ Apparent kinematic viscosity

$v_{\mathrm{o}}$ : Kinematic viscosity of silicone oil

$v_{\mathrm{w}}$ : Kinematic viscosity of water

\section{REFERENCES}

1) M. Shitara, M. Iguchi, K. Takano, T. Tamamori, H. Shitara and T. Maruyama: Mater. Trans., 44 (2003), No. 12, 2456.

2) M. Shitara, M. Iguchi, K. Takano and T. Tamamori: Proc. 16th Int. Symp. on Transport Phenomena, Pacific Center, Hawaii, (2005), in press.

3) M. Shitara, M. Iguchi, K. Takano and T. Tamamori: Proc.7th Organized Multiphase Flow Forum, Jpn. Soc. Multiphase Flow, Osaka, (2003), 35.

4) Y. Kato, K. Nakanishi, T. Nozaki, K. Suzuki and T. Emi: Tetsu-toHagané, 68 (1982), 1604.

5) G. G. K. Murthy, S. P. Mehrorta and A. Ghosh: Metall. Trans. B, 19B (1988), 839.

6) M. P. Schwartz: Chem. Eng. Sci., 45 (1990), 1765

7) Y. Xie and F. Oeters: Steel Res., 63 (1992), 227.

8) M. Iguchi, S. Hosohara, T. Koga, R. Yamaguchi and Z. Morita: Tetsu-to-Hagané, 78 (1992), No. 12, 1778 and ISIJ Int., 33 (1993), No. 10, 1037.

9) M. Iguchi, Y. Itoh and Z. Morita: Tetsu-to-Hagané, 80 (1994), No. 3, 189.

10) M. Iguchi, Y. Eguchi, A. Kawasaki, S. Kitamura and Z. Morita: ISIJ Int., 39 (1999), No. 8, 767. 
ISIJ International, Vol. 45 (2005), No. 8

11) T. Tamamori, M. Iguchi and M. Shitara: Tetsu-to-Hagané, 91 (2005), No. 1, 236.

12) Handbook of Chemical Engineering, ed. by Soc. Chem. Eng. Jpn., Maruzen, Tokyo, (1988), 905.

13) T. Vermulen, G. M. Williams and G. E. Langlois: Chem. Eng.
Progress, 51 (1955), 81F.

14) A. Kimura and H. Ohashi: Trans. Jpn. Soc. Mech. Eng., 44 (1978), 3024, 3446.

15) Handbook of Fluid Dynamics, ed. by Jpn. Soc. Fluid Dynamics, Maruzen, Tokyo, (1987), 720. 